\section{Agrochemicals Protecting Crop, Health, and Natural Environment}

\section{by N.A. Shakil and Jitendra Kumar}

Today, there is an urgent need to apply advances made in crop production research and formulate strategies to achieve the ultimate goal of more food, nutrition, higher income, and employment. New concepts in crop protection systems and augmentation in green chemistry, biotechnology, and related sciences are likely to boost agricultural productivity. Further, environmental challenges posed by pest resurgence and toxic pesticides need to be resolved using ecofriendly and economically viable technologies.

The First International Conference on Agrochemicals Protecting Crop, Health, and Natural Environment was held 8-11 January 2008 at the Indian Agricultural Research Institute, in New Delhi, India. The conference centered around several major topics, including agricultural production, introduction of better and improved crop varieties, and the use of biotechnology and nanotechnology for the betterment of crop health and the environment. The National Organizing Committee was chaired by S.A. Patil, director of the Indian Agricultural Research Institute, New Delhi. The conference attracted scientists from all over the world, teachers, research scholars, and students, who showed tremendous enthusiasm toward the subject matter.

The conference, which was IUPAC sponsored, was attended by 468 scientists from 30 countries. The participation of a large group of young scientists and students was a welcome sign. The scientific program consisted of 26 technical sessions consisting of 17 plenary lectures, 33 invited lectures, 48 oral presentations, and 208 poster presentations. Among the many topics covered in the conference program were New Generation Synthetic and Natural Agrochemicals; Agrochemicals Delivery Systems towards Occupational and Environmental Safety; Organic Approaches to Pest Management; and Agrochemical Detection, Analysis, and Quantification. The following plenary lectures give a sense of the overall quality of the conference.

The opening session began with a talk by Shri Kanti Lal Bhuria, minister of State for Agriculture, Consumer Affairs, Food and Public Distribution in India. He relayed his genuine interest in pursuing economically viable pest management strategies with minimal reliance on synthetic pesticides.

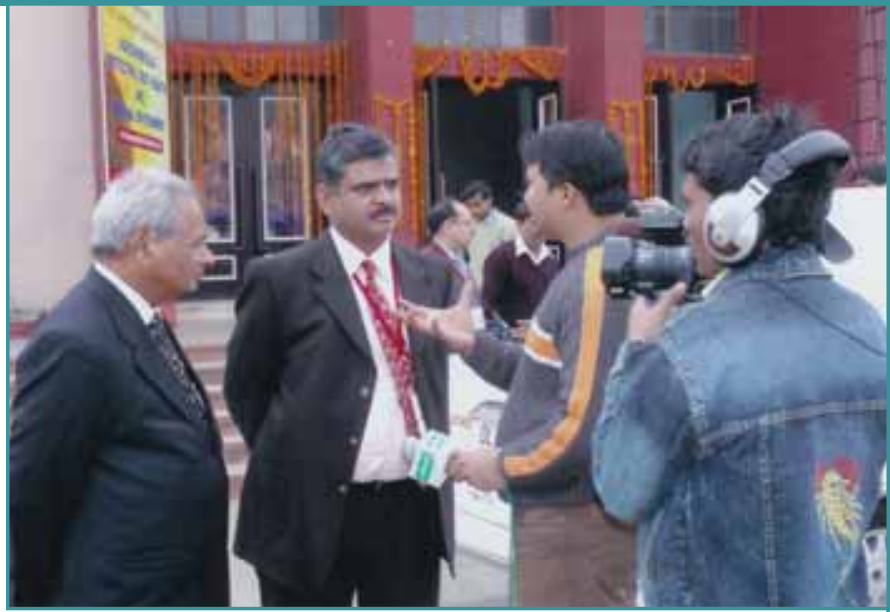

Dr. S.A. Patil (left) and Dr. N.A. Shakil (right) responding to reporters questions during an interview with Indian television.

The first plenary lecture was delivered by Kenneth D. Racke. He spoke about Good Agricultural Practice (GAP), which results in minimum residues on harvested food, and about the Maximum Residue Limit (MRL) as a regulatory standard that reflects GAP and allows control of pesticide use and residues in food. Racke explained how the world Trade Organization, through a 1995 agreement on the application of Sanitary and Phytosanitary Measures, identified Codex MRLs as the official reference for food safety issues that affect international food trade. Racke pointed out that a number of countries now actively applies Codex MRLs for regulation of pesticide residues in imported foods. Some food associations and traders have adopted private standards and food policies to avoid disharmony between major food-exporting and food-importing regions, but these policies may undermine science-based approaches. In the end, he said, creative approaches must be adopted to develop a more harmonized international approach towards regulation of pesticide residues in food if the benefits of global free trade are to be realized.

Plenary lecturer A.M.R. Gatehouse, of the school of Biology, Institute for Research on Environment and Sustainability, UK, emphasized the role of biotechnology in crop protection to achieve increased crop yields in a sustainable and cost-effective way. Her lecture dealt with the role of recombinant DNA technology in crop protection, with an emphasis on the use of insect-resistant transgenic crops.

Martin Gibson, stewardship director of Croplife Asia, Bangkok, Thailand, enriched attendees' understandings about crop protection product safety and associated benefits. His plenary lecture identified the 


\section{Conference Call}

"drivers for change" and the stakeholders who are contributing to changing how food is produced. A crucial element in protecting crops from the effects of disease, insects, and weeds in modern agriculture is the use of hi-tech crop protection products. He talked about the principles of integrated pest management, including intervention only to avoid unacceptable economic losses.

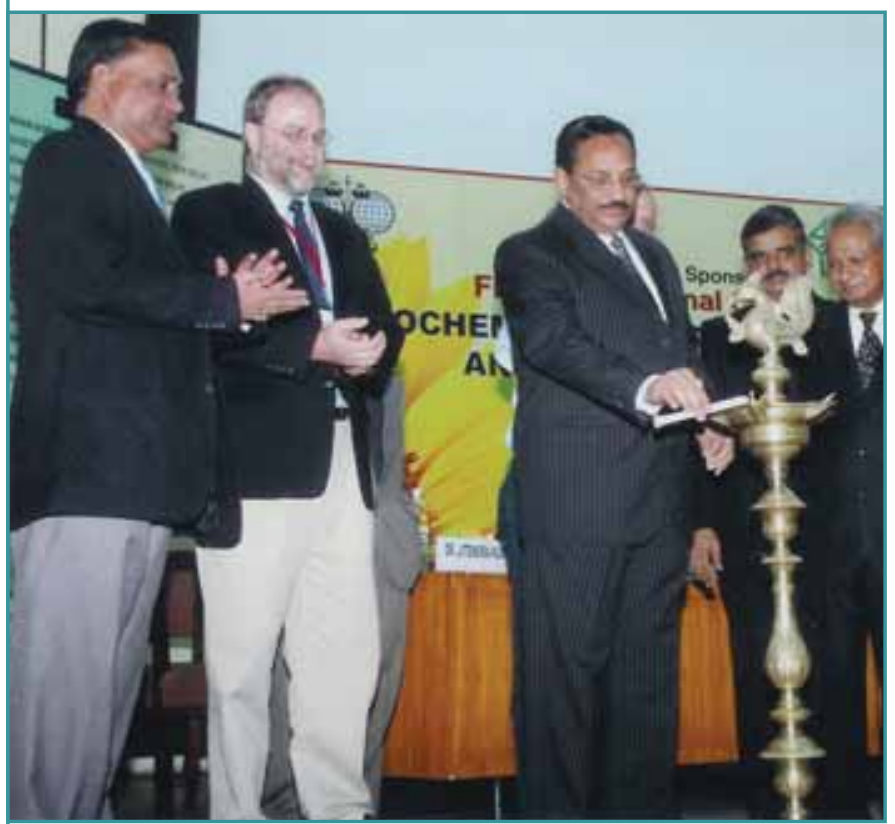

Chief Guest Shri Kanti Lal Bhuria, Minister of State for Agriculture, Consumer Affairs, Food and Public Distribution in India, is shown lighting one of the ceremonial candles to inaugurate the conference.

The topic of Denis Hamilton's plenary lecture was "The JMPS Process for Setting Pesticide Specifications." As he explained, the Joint Meeting on Pesticide Specification has issued new specifications for agricultural pesticides. The new procedure for evaluating pesticides deals with all the relevant data on the physico-chemical and hazardous properties of pure active ingredients and technical material and comparative assessment of the impurities and toxicological profile. The summary of relevant data and the data evaluation are now published as an integral document for each pesticide, available at <www.fao.org/ ag/AGP/AGPP/pesticid/> and <www.who.int/whopes/ quality/newspecif/en>.

Ronald Parker, senior environmental engineer in the U.S. Environmental Protection Agency's Office of Pesticide Programs, Washington D.C., USA, gave a plenary lecture on "Practical Tools and Methods for Evaluating Ecological Impact of Pesticides." He described a pesticide risk assessment and training module that is being developed by the Joint FAO/ IAEA Pesticide Program with assistance from IUPAC. The module is designed to provide "one step shopping" for conducting an evaluation of ecological risk from pesticide use.

V.S. Parmar, head of the Department of Chemistry, University of Delhi, India, delivered a lecture on "Biocatalytic Synthesis of Novel Pharmaceutically and Agriculturally Important Nanomaterials." He pointed out that biocatalytic reactions in synthetic sequence provide unique advantages of efficacy, economy, and environmental friendliness. A few highly novel amphiphilic polymers based on PEGs having a broad range of chemical functionality have been prepared that aggregate in aqueous medium to form a nanosphere, which is found to be useful in encapsulation of small hydrophobic drugs.

Pam Marrone, Marrone Organic Innovations, delivered her plenary lecture on the topic "Discovery, Development, and Marketing of Pesticidal Natural Product." She provided an overview of the market for biopesticides, described biopesticide discovery screening and development, outlined some examples of successful biopesticides in the market, and discussed barriers to adoption.

Ronald J. Nachman, Areawide Pest Management Research Unit, Southern Plains Agricultural Research Center, U.S. Department of Agriculture, lectured on "Stereochemical Aspects of the Interaction of Neuropeptide Agonists/Antagonists with Arthropod Receptors and Mimetic Analog Development for Pest Control." He addressed the stereochemical and conformational aspects critical for the successful interaction of the two classes of arthropod neuropeptides with their respective receptors, using either expressed receptor cell lines or bioassays. This information is then used to design and develop mimetic analogs of these insect neuropeptide classes with enhanced biostability, bioavailability, and selectivity. The effects of a selected number of mimetic analogs on physiology of insects are also discussed.

During the closing ceremony, the following recommendations were formally adopted:

1. Role of Agrochemicals: It was resolved that the use of agrochemicals, whether of natural or synthetic origin, is indispensable for protecting crop health and natural environment and to feed the 
burgeoning population of the world. Therefore, innovative efforts to discover, develop, and formulate conventional or novel molecules to yield ecologically benign products need to be vigorously pursued and promoted to meet the needs of the future.

2. Introduction of New Technology: Approaches such as biotechnology, nanotechnology, and the like need to be carefully introduced for agricultural applications after careful evaluation of the benefits and risks, and identification of stewardship practices to accompany practical implementation.

3. Biopesticides: The simple assumption that biopesticides must be inherently safe for humans and the environment due to their natural origin is not correct. As for any crop protection product, biopesticides should be subject to evaluation and scrutiny for safety based on applicable data requirements.

4. Harmonization: International standards and guidelines for pesticide quality, safety, and environmental testing, and limits for residues in food are being developed under the auspices of such advisory bodies as FAO, WHO, CODEX, and OECD. Based on the increasing globalization of trade for both agrochemicals and food, it is recommended that national authorities and industry cooperate to the greatest extent possible in supporting and adopting such harmonized approaches. International advisory bodies should in turn monitor closely the emergence of new technologies and commodities and develop appropriate standards in a timely fashion to meet changing needs.

5. Sustainability: Sustainable agriculture requires the adoption of good agriculture practice, product stewardship, and integrated pest management on a widespread scale. Theory and methods are in place and pilot projects have demonstrated the feasibility of such approaches. It is recommended that governments, academia, and industry develop intense co-operation so as to implement these practices on a much broader basis and with a high sense of priority.

N.A. Shakil <iamshakil@gmail.com> and Jitendra Kumar are senior scientists in the Division of Agricultural Chemicals, Indian Agricultural Research Institute, New Delhi, India; they were conveners of the conference.

\section{Improving Chemical Education in the Philippines}

\author{
by Fortunato B. Sevilla III
}

A two-day conference on Improving Chemical Education in the Philippines was held at the University of Santo Tomas in Manila, Philippines, from 17-18 April 2008. The conference was a project of the IUPAC Flying Chemists Program and was organized by the Commission on Higher Education (CHED), the government body covering higher education institutions in the Philippines, in cooperation with the Kapisanang Kimika ng Pilipinas (Chemical Society of the Philippines) and the University of Santo Tomas.

This conference is a follow-up activity to the revision carried out by the CHED Technical Committee for Chemistry of the curriculum for the B.S. program for chemistry. It aimed to upgrade the course delivery methods employed by chemistry teachers in the Philippines. The project was inspired by the write-ups featured in Chemistry International on the Indian and Sri Lanka projects of the Flying Chemists Program <www.iupac.org/standing/cce/FCP.html>.

Participation in the conference, a total of 324 tertiary-level chemistry teachers, was beyond expectations. Attendees came from all the regions of the country and represented 89 different institutions of higher education in the Philippines. Among the partici-

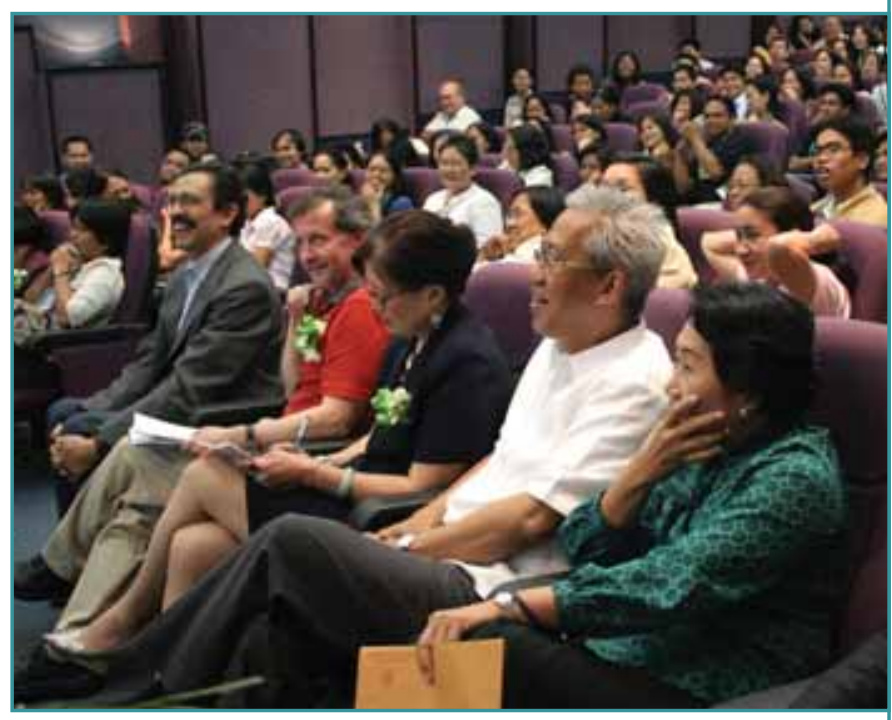

Peter Mahaffy (red shirt), chair of the IUPAC Committee on Chemistry Education, and others listen to a lecture. 